O Grande sertão nas ruínas da sala de aula: formação histórica periférica e experiência social subjetiva - um diário de trabalho

O Grande sertão in the ruins of the class room: periphery historical formation and subjective social experience - a work report

\title{
Ivan Delmanto
}

Ivan Delmanto Doutorando em Teoria e História do Teatro na Escola de Comunicações e Artes da Universidade de São Paulo (ECA-USP)

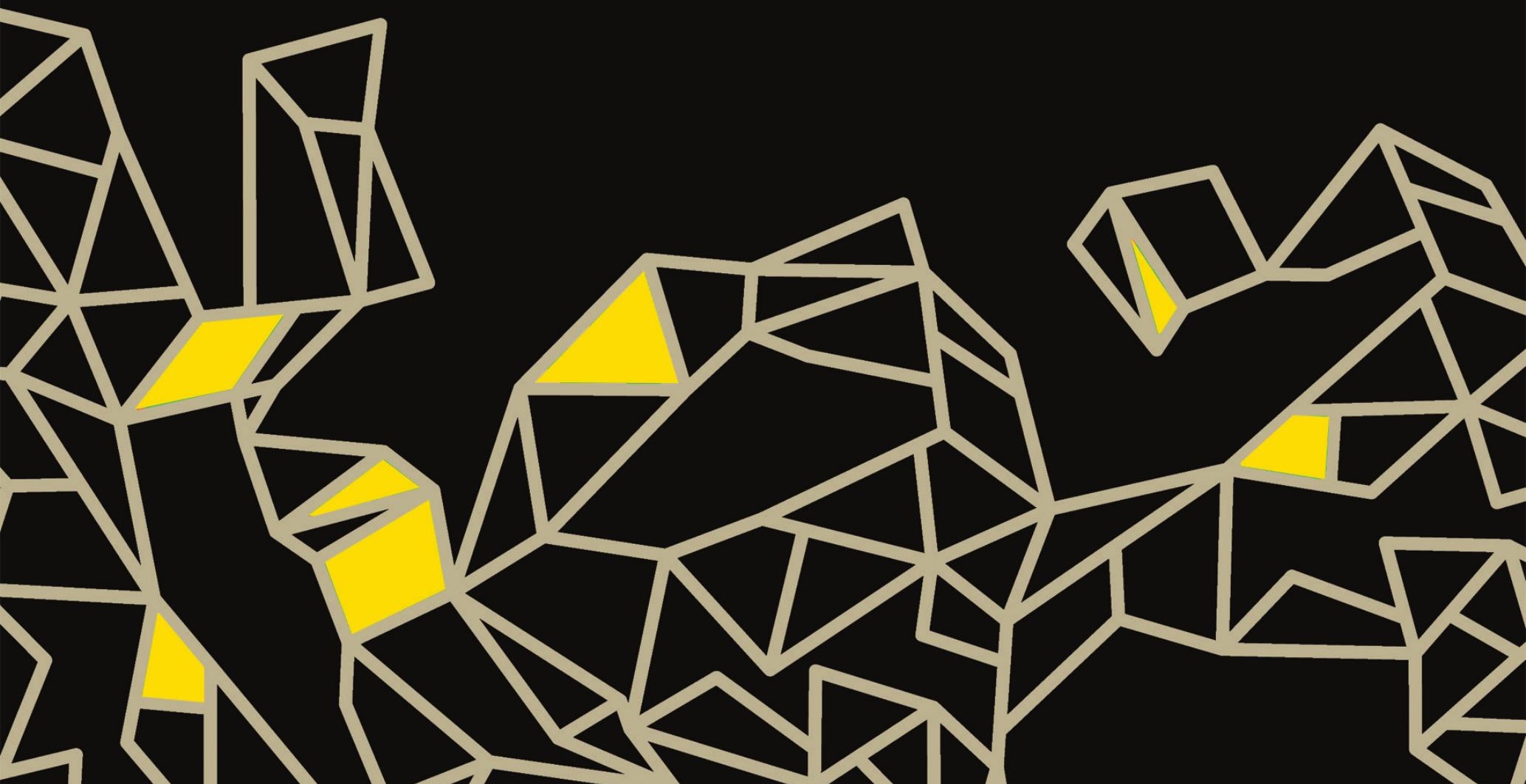




\section{Resumo}

Este artigo tem como objeto o processo de criação do espetáculo teatral Grande sertão Grajaú: veredas e ruínas. Investiga as tensas relações entre forma teatral, abordada em suas diversas e contraditórias dramaturgias, e subjetividade. Esse processo de criação tomou como pressuposto a ideia de "formação", inspirada na obra de Antonio Candido, Formação da literatura brasileira, que define, no campo das letras nacionais, a ambivalência característica do nosso processo de constituição cultural, marcado pelo empréstimo de formas artísticas importadas em desajuste com a realidade histórica local. Procuraremos identificar diversas manifestações de uma certa "dialética trágica" que, não obstante sua diversidade, poderia caracterizar esse processo de formação como capaz de gerar experiências sociais subjetivas tão dilaceradas quanto o seu tecido social correspondente.

Palavras-chave: Pedagogia, Performance, Processo criativo.

\section{Abstract}

This article aims to study the creative process of the stage show Grande Sertão Grajaú: veredas e ruínas. It investigates the tense relations between the theatrical forms, approached in its diverse and contradictory dramatic structures, and subjectivity. This creative process explores the idea of "formation", inspired by Antonio Candido's work, Formação da Literatura Brasileira (Brazilian's Literature Formation), which, in the national literary field, defines the ambivalence that exists in our cultural constitution process, characterized by the influence of imported artistic forms unrelated to the local historical realities. We will seek to identify several indications of a certain "tragic dialectic" and, notwithstanding its own diversity, how it could characterize this formation process capable of generating subjective social experiences as lacerated as the social fabric to which they correspond.

Keywords: Pedagogy, Performance, Creative process.

\section{Diário - entrada 1: verão de 2015}

O processo de criação teatral que baseia o mais recente projeto de pesquisa da II Trupe de Choque estrutura-se sobre o conceito de aula utópica 
compartilhada, no qual cada ação artística e pedagógica realizada pelo grupo, em sua residência artística no bairro do Grajaú, em São Paulo, está relacionada à criação de um espetáculo teatral em progresso. Assim, a cada ação pública proposta, a II Trupe de Choque expõe suas descobertas, suas ideias, seus fragmentos, seus conceitos e suas dificuldades, contando com a participação do público na elaboração de respostas teatrais a partir desse diálogo em constante devir criativo. Uma vez que a dramaturgia criada até agora apresenta como moldura narrativa (inspirada no romance Grande sertão: veredas, de Guimarães Rosa) uma aula dada pelo personagem Riobaldo em que este rememora sua vida e dá voz aos demais participantes de sua própria história -, o espetáculo será realizado em uma única sala de aula, permitindo-nos pesquisar, com alunos e professores das escolas que abrigam o grupo, diversos formatos capazes de expandir a experiência cotidiana de uma aula, buscando na experiência artística e performativa novos processos de aprendizado coletivo. O espaço da sala de aula também é transformado em busca de uma encenação performativa, capaz de dar forma às cenas rememoradas por Riobaldo e pelos outros narradores, que se passam no espaço aberto do sertão. A fusão entre o sertão e as escolas do Grajaú estabelece, assim, uma convulsão de tempos e de espaços.

Após termos nos deparado com diversas versões do mito ideológico que situa o Brasil como o país do "encontro marcado com o progresso", nossa pesquisa partirá da pergunta: "e se o aspecto da modernização que nos coube, assim como a outros países, for o desmanche ora em curso, fora e dentro de nós? E quem seríamos nós neste processo?". Estabelecer "quem somos nós" tornou-se o eixo central da pesquisa da II Trupe de Choque.

O grupo pretende criar uma dramaturgia e uma encenação inéditas, a partir de um estudo do romance de João Guimarães Rosa. A hipótese principal sustentada é a de que Grande sertão: veredas é um romance de formação (Bildungsroman), que pode ser lido como história criptografada do Brasil. Para tanto, acreditamos, a partir de estudos de Willi Bolle (2004) e de José Antônio Pasta Jr.(1999), que a narrativa de Rosa reescreve, na perspectiva do "esquecimento ativo", Os Sertões, de Euclides da Cunha, bem como dialoga e polemiza com ensaios sobre a formação nacional, de autoria de Gilberto Freyre (2004), Sérgio Buarque de Holanda (2005), Caio Prado Jr.(2000), 
Celso Furtado (2011), Antonio Candido (1975) e Raymundo Faoro (2008). Tais ensaios estão sendo estudados durante a pesquisa e embasam o trabalho artístico-pedagógico que o grupo desenvolve nas escolas que sediam o processo criativo.

\section{Dário de trabalho - entrada 2: outono de 2016}

Grande sertão: veredas foi escolhido, portanto, como material de estudo por apresentar, em sua estrutura narrativa mais ampla, um contínuo debater-se sobre a antiga questão, surgida durante o romantismo, da identidade nacional. A narrativa contada por Riobaldo Tatarana parece perguntar-nos a todo o tempo: como é possível que, na sociedade brasileira, o governo dos donos da vida exija daqueles que são dirigidos, para além dos atos de obediência e de submissão, aquilo que Michel Foucault chamou de "atos de verdade" (FOUCAULT, 2014, p.75), que têm como particularidade o fato de que não somente o sujeito é obrigado a dizer a verdade, mas a dizer a verdade sobre si mesmo, suas faltas, seus desejos, seu estado de alma? A narração de Riobaldo nos leva a perguntar não apenas as razões do seu ato de contar, mas também sobre como se formou um tipo de sociedade em que não é mais exigido simplesmente obedecer, mas manifestar-se, enunciando aquilo que se é.

Nesse sentido, o romance de Rosa faz com que a célebre questão kantiana - "descobrir o que somos nós" (KANT, 2016) - seja desterritorializada, e a pergunta principal passa a ser outra: "como chegamos a ser o que somos?". É com essa pergunta que pretendemos abordar o Grande sertão, procurando abrir a possibilidade radical de contestarmos aquilo que somos, de lutarmos para não sermos mais o que fomos até agora e de buscarmos outras formas de ser e de estar no mundo. A dimensão artístico-pedagógica deste projeto parte também desses princípios presentes no ato de narrar em sala de aula, realizado por um desmemoriado Riobaldo.

A II Trupe de Choque busca aproximar o conceito de "sertão", utilizado por Rosa, à realidade urbana das periferias de São Paulo, representada, no nosso caso, pelo bairro do Grajaú, como uma espécie de microcosmo do Brasil no presente e de suas contradições. Apesar de pesquisas recentes comprovarem que os lugares mencionados pelo autor mineiro no seu romance 
podem ser todos identificados na geografia concreta da região do norte de Minas Gerais, na narrativa de Rosa há uma impossibilidade de se traçar com precisão os limites do sertão mencionado por Riobaldo: "o sertão não tem janelas nem portas. E a regra é assim: ou o senhor bendito governa o sertão, ou o sertão maldito vos governa” (ROSA, 2001, p. 544).

Em busca de respostas para nossa investigação, abandonamos a pretensão de retratar de forma linear qualquer espécie de processo de formação brasileiro, ou de uma identidade brasileira, já que pudemos identificar no país um acúmulo de realidades convivendo em contradição, de maneira que do atraso das relações sociais se fez base de sustentação (e de exploração) para formas de sociabilidade modernas. O objetivo agora é continuar recriando o material textual do romance Grande sertão: veredas, de João Guimarães Rosa, acreditando que por meio do atrito entre literatura e realidade periférica do Grajaú poderemos descobrir procedimentos artísticos capazes de dar conta da peculiar realidade nacional.

As escolas estaduais foram escolhidas como sedes das atividades do grupo e como espaços não convencionais para a criação e a apresentação do espetáculo exatamente por serem capazes de alegorizar o tema central de pesquisa, no que diz respeito à formação dessa subjetividade brasileira. Assim, sendo um projeto que trata da (de)formação do país, decidimos situá-lo no espaço, por excelência, de formação de sujeitos da sociedade ocidental: a escola. Dando continuidade à história do grupo, que já ocupou outros espaços disciplinares, como uma usina de compostagem de lixo, por quatro anos, e um hospital psiquiátrico, por cinco anos, a escolha das escolas como espaços cênicos vem da possibilidade de nos perguntarmos, dentro dessa instituição disciplinar, sobre a formação brasileira, sobre "quem somos nós" e sobre o processo histórico que nos "formou" até aqui.

Partimos da hipótese de que a importação dos modelos de sociabilidade surgidos na Europa, assolada por um processo histórico altamente contraditório e desigual, teria sido expressa, entre nós, por diversas formações sociais fraturadas, que poderiam ser reveladas por um conceito ampliado de tragédia. Se não estivermos enganados, seria possível identificar, nesse percurso histórico brasileiro, diversas manifestações de uma certa dialética trágica 
que, não obstante sua diversidade, poderia caracterizar esse processo de formação singular.

Segundo Peter Szondi (2004), outro de nossos interlocutores fundamentais, a tragédia seria definida pela figuração da contradição: no gênero trágico, a consciência da dualidade é a consciência da cisão. A consciência da dualidade insolúvel, sem síntese possível. Uma dialética sem superação, dialética truncada ou estagnada, cuja melhor definição se encontra, segundo Jose Antonio Pasta Jr. (1999, p. 62), num "regime de dualidade", num regime de representação modalizado pelo ritmo da ambivalência em que os conflitos permanecem ecoando uns sobre os outros:

O trágico é um modus, um modo determinado de aniquilamento iminente ou consumado, é justamente o modo dialético. É trágico apenas o declínio que ocorre a partir da unidade dos opostos, a partir da transformação de algo em seu oposto, a partir da autodivisão. Mas também só é trágico o declínio de algo que não pode declinar, algo cujo desaparecimento deixa uma ferida incurável. Pois a contradição trágica não pode ser superada em uma esfera de ordem superior - seja imanente ou transcendente. (SZONDI, 2004, p. 34, grifos do autor)

Tentamos, a partir desse conceito de tragédia, identificar certo processo de deformação histórica no Brasil. Para tal, pretendemos abordar o material do romance Grande sertão: veredas como um material trágico. Testar o conceito de tragédia para ler tais experiências, as históricas e as configuradas no romance no espaço da ficção, tratar-se-ia de uma tentativa de figurar o processo interno que estrutura todas as relações constitutivas de nossa nacionalidade - o nosso processo particular de constituição histórico-social marcado pela "modernização conservadora", em que as heranças de país colonial, escravocrata e patriarcal jamais são superadas; ao contrário, são agravadas com a passagem do tempo.

Surgiu-nos nesse momento a hipótese - ainda a ser testada incessantemente durante a pesquisa - de que o jogo das oposições impõe à forma trágica um infindável movimento pendular - similar ao da antiformação brasileira - entre extremos que nunca encontram um momento de síntese. Os conflitos seriam assim registrados em movimento cíclico permanente, que poderia ser designado pelas expressões "eterno retorno do mesmo" ou "eterno retorno 
da ruína”, em que a aparência e a essência, o interior e o exterior se confundem de maneira quase indissolúvel. Percebemos, já nessa segunda etapa da pesquisa, que para tratar do Brasil estávamos diante de nós mesmos, desses sujeitos monetários sem dinheiro, e de uma experiência social subjetiva totalmente diversa.

\section{Diário de trabalho - entrada 3: inverno de 2016}

Essa espécie de falência social no Brasil geraria também uma subjetividade falida, trágica, mas antidramática por excelência, para falarmos em termos teatrais, por não dar dimensão ao conceito de indivíduo. Seria trágica, por ser contraditória e traumática. Pensamos aqui em trauma como a intrusão violenta de qualquer coisa de radicalmente inesperado, qualquer coisa para a qual o sujeito não estava em absoluto preparado e que ele não pode integrar de maneira alguma.

Talvez estejamos diante de um país em que o trauma é o estado de coisas permanente, um modo de vida. Os sujeitos não têm maneira de escapar dele e não podem sequer dizer que estão sendo perseguidos pelo fantasma de um trauma anterior: o que permanece não é o fantasma do trauma, mas o próprio trauma. Slavoj Zizek chamou esses sujeitos de pós-traumáticos, comparando-os às vítimas de Alzheimer e de outras lesões cerebrais:

Não há continuidade entre esse novo sujeito pós-traumático e a sua identidade anterior: depois do choque, é literalmente um outro sujeito que emerge. Os seus traços são bem conhecidos: ausência de investimento afetivo, indiferença e distâncias profundas - trata-se de um sujeito trágico que não está mais dentro do mundo. O sujeito vive a morte como uma forma de vida - a sua vida é pulsão de morte encarnada, uma vida desprovida de investimento erótico. (ZIZEK, 2011, p. 358-361)

Falar, no Brasil da formação trágica, em sujeitos pós-traumáticos é cometer uma imprecisão, uma vez que é precisamente a persistência do trauma que torna a sua situação tão traumática. Talvez devamos falar em um sujeito-em-trauma para definir essa subjetividade brasileira que tem características tão distintas do indivíduo burguês tradicional. É o que pretendemos testar em nosso momento atual de pesquisa. Seria possível traçar, no plano de 
uma experiência social subjetiva brasileira, um percurso de trauma contínuo que segue em paralelo ao nosso processo histórico de formação às avessas? Tal traçado de uma experiência subjetiva em trauma constante, que podemos chamar de trágica, revelaria descobertas produtivas para a criação de uma encenação, de uma dramaturgia e de uma metodologia de trabalho para o ator capazes de figurar a nossa realidade presente, de (de)formação e conformação de inúmeros sertões Grajaú? Talvez seja possível ler nas máscaras da tragédia um pouco da face não cicatrizada da subjetividade traumática brasileira, formada por prolongadas experiências sociais em sua sedimentação histórica.

O trabalho de construção dos personagens em nosso projeto de pesquisa, seja na criação da dramaturgia textual, seja no trabalho de atuação ou de encenação, testará a hipótese de que tal subjetividade trágica, tal sujeito em trauma, possa revelar aspectos importantes da realidade brasileira contemporânea. O processo de criação tentará, assim, diariamente, dar forma a essa espécie de subjetividade, concebendo imagens dialéticas capazes de plasmar tais máscaras mortuárias em ruínas.

Talvez seja possível encontrarmos na reflexão de um outro hegeliano, Jaques Lacan, novas pistas para caracterizar essa experiência histórica subjetiva dos habitantes do sertão Grajaú. Lacan (1999) escreve "Outro", com letra maiúscula, para distingui-lo do parceiro, do outro. Trata-se, então, de um lugar, que em particular é o lugar da linguagem, o lugar dos significantes, situado para além de qualquer pessoa, onde se encontra o que é anterior ao sujeito e que, entretanto, o determina. Há em Lacan diversas definições para o conceito de Outro.

Em "Subversão do sujeito e dialética do desejo no inconsciente freudiano", Lacan afirma que "é do Outro que o sujeito recebe a mensagem que ele emite" (LACAN, p. 829). Poderíamos dizer então que "é qual Outro que o sujeito deseja", ou seja, que o desejo é estruturado pelo "descentrado" grande Outro, a ordem simbólica - que o desejo é predeterminado pelo grande Outro, o espaço simbólico no qual o sujeito habita. Mesmo quando os desejos são transgressivos e violam as normas sociais, essa transgressão seria condicionada por aquilo que transgride.

Há ainda mais um desdobramento do conceito: esse outro que se aloja no âmago do Outro, em seu vagar sem representação, causando o desejo e provocando a angústia. 
Eu o chamei pequeno a porque é a inicial de outro em francês, do que se chama l'autre, exceto que, justamente não é o outro, não é o outro sexo, é o outro do desejo, é o que constitui a causa do desejo. (LACAN, 1999, p. 801)

O objeto a seria assim o suporte de tudo o que interessa o sujeito e se encontra em todos os objetos libidinizados do mundo. Esse objeto-outro que se declina segundo as pulsões é o que o sujeito busca no Outro, parceiro sexual, para satisfazer à exigência pulsional. Não há "acesso ao Outro do sexo oposto", diz Lacan, "senão pela via das pulsões parciais através das quais ele busca um objeto que Ihe reponha essa perda de vida que lhe é própria por ele ser sexuado" (LACAN, 1999, p. 803). Efeito da linguagem, o objeto a seria então parte integrante da fantasia, única lente por meio da qual apreende-se a realidade.

Talvez pudéssemos abordar o sentido de Outro relacionando-o aqui ao objeto a. Em nossos primeiros esboços de cena, cada interioridade arruinada dos personagens não consegue se relacionar verdadeiramente com o outro sujeito, estando presa aos ditames do Outro como lei (lei e Estado nascente liberal) e do Outro como regime de reprodução social. Essa subjetividade que age e se move, permanecendo sempre a mesma, seria uma subjetividade dilacerada e infeliz, perdida em meio às contradições insuperáveis da ordem histórica do país. Nesse sentido, talvez seja possível relacionar o objeto a lacaniano, esse objeto de desejo anterior e determinante de toda a linguagem, a um objeto traumático: o próprio sistema capitalista brasileiro, fusão entre modernidade financeirizada e espoliação bruta do trabalho, que não consegue emergir como trauma porque permanece obscuro e apagado, como um fantasma, por mais que determine cada desejo dos sujeitos.

Esta é também uma das maneiras de explicar o sentido da asserção lacaniana do "descentramento" constitutivo do sujeito. Seu argumento não é que minha experiência subjetiva está regulada por mecanismos inconscientes objetivos que estão descentrados em relação com minha autoexperiência e, como tais, fora do meu controle; senão que é algo muito mais inquietante, a saber, que estou privado inclusive de minha mais íntima experiência "subjetiva", a do fantasma fundamental que constitui e garante o centro de meu ser, posto que não me é possível experimentá-lo e assumi-lo nunca. (ZIZEK, 2011, p. 116) 
Para Zizek (2011, p. 245), seguindo pistas de Lacan, a concepção usual da subjetividade é a da (auto)experiência fenomênica: "sou um sujeito desde o momento em que posso dizer-me a mim mesmo: não importa que mecanismos desconhecidos governem meus atos, percepções e pensamentos; ninguém pode tirar-me o que vejo e o que sinto agora". O argumento de Zizek (2011, p.54), ainda retomando Lacan, seria de que o psicanalista é aquele que, precisamente, pode acabar com essa ilusão e tem como objetivo último privar o sujeito de seu próprio fantasma fundamental que regula o universo de sua (auto)experiência. O sujeito do inconsciente freudiano surgiria somente quando um aspecto capital da (auto)experiência fenomênica do sujeito, seu fantasma fundamental, se torna inacessível, isto é, "primordialmente reprimido". No que tem de mais radical, o inconsciente seria o fenômeno inacessível, não o mecanismo que regula a experiência cotidiana. "É essa inacessibilidade que converte o sujeito em vazio" (ZIZEK, 2011, p. 94). Em outras palavras, nos é permitido assim formular uma "fenomenologia sem sujeito: aparecem fenômenos que não são fenômenos de um sujeito, que não aparecem (auto)conscientes para esse sujeito" (ZIZEK, 2006, p. 34). Isto não quer dizer, ao contrário do que afirmam alguns ideologemas pós-modernos, que o sujeito está morto. $\mathrm{O}$ sujeito, para Zizek (2006, p. 98) estaria presente, mas na forma de exclusão, como instância negativa que não é capaz de assumir tais fenômenos.

É possível imaginar a transformação que tal concepção de subjetividade pode causar na maneira de construir personagens teatrais. Sob tal princípio, a célula da criação do personagem deixa de ser a ação, gerada por objetivos conscientemente formulados pelo ator que representa o papel. Estaríamos diante de zonas cinzentas que baseiam as atitudes de cada personagem. Mas o que é o personagem em uma concepção de sujeito que envolve o fantasma? O fantasma é, por definição, não objetivo, no sentido mais simples de "existir independentemente das percepções do sujeito". Mas, por outro lado, é também não subjetivo, no sentido de ser reduzido às intuições conscientemente experimentadas pelo sujeito. O fantasma seria para a criação do personagem uma categoria essencialmente negativa, o que há de inacessível e de vazio no personagem.

Para a criação de um personagem baseada nesse princípio, caberia ao ator e ao dramaturgo formular o que o sujeito é incapaz de identificar, ou 
formular o vazio. $O$ vazio seria esse conteúdo traumático da subjetividade brasileira, encoberto por modos de produção sobrepostos, que teria como núcleo o desejo inconfessável e fantasmático do domínio sobre o outro como escravo. Há um pequeno rascunho de cena, produzido em sala de ensaio pelos integrantes da II Trupe de Choque, que procura expor algumas das contradições mencionadas:

NO JULGAMENTO PELA GUARDA DO FILHO, Riobaldo se defende das acusações de Diadorim:

RIOBALDO URUTU BRANCO - Não sou eu quem fala, somos nós. Não há eu aqui. Apenas nós. Aprendemos com nossas experiências passadas: a tentativa dos primeiros povos dessas terras, nossos ancestrais, foi de tentar se transformar no inimigo invasor e português, imitando-os, em um exercício de alteridade absoluta.

DIADORIM - Foi o que encontramos quando chegamos aqui, você mudou a Lei, prendendo e assassinando quem discorda.

URUTU BRANCO - Nós prendemos. Nós assassinamos. Nós mudamos, Diadorim, você também. Estamos acossados, cercados pelo inimigo e precisamos sobreviver. Veja aqueles índios, que abrigamos aqui, com suas favelas e malocas: a alteridade absoluta não vence. A militarização vence. Não somos nós quem dizemos: são os quilombos, são os escravos comunistas de Prestes, são os farrapos de Canudos: quem está embaixo precisa se formar... Educar-se é nadar no sangue inimigo para destruir.

DIADORIM - Por que acreditam que só é possível resistir em forma de tropa? Não é possível resistir pelo amor, como Cristo?

URUTU BRANCO - Cristo fede. Cristo é o indivíduo burguês, sozinho e desamparado, transformado em Deus. Você vai perder a criança, que não te pertence. $E$ vai perder a vida para o Coletivo; os dogmas não te pertencem.

DIADORIM - E quem julga que estou errada? Deus? O Urutu Branco?

URUTU BRANCO - Nós dizemos. E podemos dizer porque somos uma só voz de muitas vozes, um só monstro de muitas cabeças, e falamos do ponto de vista do Futuro.

DIADORIM - Fala do ponto de vista do Juízo Final.

URUTU BRANCO - Nossa religião é a revolução, e minha espada é a guerra. Você tem a opção de confessar. Escreva e será preservada.

DIADORIM - Eu não quero que me preservem. Quero ser condenada. Quero morrer. (Risos na plateia) Não vou me matar com um tiro porque vão dizer que me matei para prejudicar o Coletivo. Mas se eu morrer, por assim dizer, por motivo de doença, o que vocês têm a perder? (Risos.) 
VOZES - Chantagista!

ZÉ BEBÊLO - Seu patife! Cale essa boca! Que baixeza! Como ousa falar assim?

DIADORIM - Mas vocês precisam entender... É muito difícil para mim continuar... vivendo.

URUTU BRANCO - E é fácil para nós?!

ZÉ BEBÊLO - Ouviram isso: "não vou me matar com um tiro, mas vou morrer"?!

DIADORIM - É fácil para vocês falar de mim. Afinal de contas, o que perdem com isso? Vejam, se eu fosse uma sabotadora, uma traidora, então por que me poupariam? Não estou pretendendo nada com isso. Só estou descrevendo o que se passa na minha cabeça, o que estou passando. Se de alguma forma isso provocar algum prejuízo político, por menor que seja, então não tem problema, eu faço o que me disserem. (Risos.) Por que estão rindo? Não tem absolutamente nada de engraçado nisso.

ZÉ BEBÊLO - Essa resposta provocou tamanho acesso de riso nos nossos magistrados que a senhora (ou o senhor, como queira) terá que rir também. As pessoas se dobram com as mãos nos joelhos e sacodem-se como se tivessem espasmos de tosse. Ninguém decide nada por si aqui. Quem decide sua sentença é o Tribunal Solidário. Sua pretensa autonomia é sinal de individualismo.

DIADORIM - Minha morte é a morte de qualquer individualismo. E é também a morte do coletivismo de vocês. Do coletivismo militar. Da vida sem cadáveres, com corpos vomitando sangue nas valas comuns.

URUTU BRANCO - NÓS! FALE NÓS! Você é uma de nós! Sem identidade, sem propriedade, sem vida individual, você faz parte do horror que diagnostica!

DIADORIM - Ainda tenho algo que não pertence a essa Fazenda arruinada: minha morte.

ZÉ BEBELO - Prendam-na! Não a deixem morrer. A sentença está promulgada: ela vai viver. (II Trupe de Choque, 2016)

A cena acima trata de um julgamento, realizado por jagunços, que decidirá quem tem direito à guarda do filho do casal Riobaldo e Diadorim. No entanto, essa estrutura objetiva, regida por preceitos da filosofia do Direito que baseiam o Estado democrático, é afirmada e negada a cada réplica: o juiz (Zé Bebêlo) confunde-se com o ponto de vista de acusação de um dos litigantes (Riobaldo); a causa em questão (guarda do filho) é abandonada porque no meio do processo a outra litigante (Diadorim) é transformada em 
réu de um outro processo: o de crime de opinião. O discurso de Riobaldo, de viés stalinista (a cena inspirou-se no julgamento de Bukharin, presidido por Stalin durante os expurgos de 1938, que devastaram a oposição ao estado Soviético), confunde-se com um certo retrato do sistema patrimonialista, que unia a figura dos coronéis aos seus apadrinhados por meio das funções judiciais, médicas, de trabalho e de proteção, todas fornecidas pelo coronel. Riobaldo não possui identidade porque, à feição de um coronel, sua subjetividade abarca todas as vozes do poder, sem fixar-se em nenhuma - daí a dificuldade de sua oposição.

A cena criada pela II Trupe tem antepassado em outra dramaturgia: um certo julgamento escrito por "Vianinha" e presente no segundo ato de Os Azeredo mais os Benevides (VIANNA FILHO, 1968). A cena assume teor grotesco ao mostrar um litígio entre dois camponeses que brigam por causa de um porco. A cena lembra a peça "O juiz de paz na roça", de Martins Pena (1990), a que provavelmente se refere como uma citação dramatúrgica. O diálogo entre os reclamantes ilustra bem o tom alegórico que remete diretamente a questões universais:

RECLAMANTE I - O porco é meu, Doutor, que a porca que pariu ele é minha.

RECLAMANTE 2 - Mas, Doutor, o porco pai é meu...

ALBUQUERQUINHO - Porco pai, não é?...

RECLAMANTE I - Mas o porco dele foi dormir com a minha porca no meu terreiro!

RECLAMANTE 2 - Meu porco foi lá, mas sua porca deu o fiofó prá ele porque quis...

OS DOIS - Seu porco é desabusado! - Sua porca é sem vergonha! (VIANNA FILHO, 1968, p. 52-53)

O olhar melancólico do dramaturgo petrifica a ação de uma disputa jurídica que não se relaciona à unidade de ação principal da peça , pautada pela amizade de Espiridião e do trabalhador Alvimar. Albuquerquinho, representante do mundo urbano, não possui trajetória na narrativa e surge nesse momento para participar da situação de disputa que alegoriza o poder judiciário no país. Para resolver a contenda, diz o juiz: 
ALBUQUERQUINHO - Não aguento mais, não quero ser juiz. É impossível fazer justiça. Todos têm razão. Já gastei duas vezes o meu ordenado. Chega. Quero ir para o Rio de Janeiro fazer footing na Praia do Flamengo comendo flocos.

MÃE - Ah, é, então temos um candidato a governador da Bahia, conseguimos fazer de ti um juiz, Deus sabe como e queres ir comer flocos na Praia do Flamengo? (Ibid., p. 53)

Percebemos nesse outro fragmento, passado agora no espaço privado da família, que o juiz possui um método particular de administrar a justiça: pagar aos litigantes. Por meio do favor, Albuquerquinho consegue apadrinhar os miseráveis lavradores que recorrem ao tribunal, obtendo o controle de suas vidas e força de trabalho para futuros empreendimentos, legais ou ilegais. A alegoria termina com o retrato do sistema patrimonialista, que unia a figura dos coronéis aos seus apadrinhados por meio das funções judiciais, médicas, de trabalho e de proteção, todas fornecidas pelo coronel. Para além dessa temática, o que nos interessa no fragmento é perceber como o dramaturgo retrata formalmente a situação: em breves diálogos, por meio de uma cena sintética, que se passa em dois espaços diferentes e consegue, com o recurso à hipérbole que fixa o absurdo da situação, alegorizar um contexto histórico de teor universal, sem a mediação da particularidade dramática, representada pelo personagem individualizado e de subjetividade profunda e livre - base que estrutura a forma do drama e da experiência social burguesa de matriz europeia, que não é compatível com a subjetividade trágica dos Azeredos e do Grande sertão Grajaú.

Segundo Francisco de Oliveira (2003, p. 67):

A industrialização, em sendo tardia, se dá num momento em que a acumulação é potencializada pelo fato de dispor, no nível do sistema mundial como um todo, de uma imensa reserva de trabalho morto que, sob a forma de tecnologia, é transferida aos países que iniciaram o processo de industrialização recentemente. Assim, na verdade, o processo de reprodução do capital "queima" várias etapas, entre as quais a mais importante é não precisar esperar que o preço da força de trabalho se torne suficientemente alto para induzir as transformações tecnológicas que economizam trabalho.

A presença de tal processo de modernização conservadora, de formação trágica, poderia ser vista em formas desconjuntadas de dramaturgia, capazes 
de incorporar ao seu tecido formal e à experiência subjetiva dos personagens a permanência do trauma histórico que o cotidiano no sertão expressa.

O salto dialético proposto por Francisco de Oliveira é a demonstração de que essas contradições, inauguradas com a convivência entre ideário liberal, forma-mercadoria e escravidão, não se baseiam em vestígios do passado, mas são partes funcionais do desenvolvimento moderno do país, uma vez que contribuem para o baixo custo da mão-de-obra em que se apoia a nossa geração de riqueza. A precariedade das formas sociais do atraso não seria apenas uma herança arcaica que arrastaríamos como fardo, mas seria, isso sim, essencial à acumulação econômica que caracteriza nossas feições sociais. Nosso processo histórico seria, assim, formado por uma simbiose e uma organicidade, uma unidade de contrários, em que o chamado "moderno" cresceria e se alimentaria da existência do "atrasado". Para os países colonizados e depois subdesenvolvidos, essa configuração é central, pois estes foram incorporados ao mundo moderno, leia-se, ao mercado mundial, na qualidade de países econômica e socialmente atrasados (fornecedores de matéria-prima e de trabalho barato). Seguindo agora Paulo Arantes, a ligação desses países com o novo se faz através do atraso, que assim se torna estrutural e, em lugar de se extinguir, se reproduz, como atesta a industrialização recente dos países africanos. $O$ tradicional torna-se, assim, pura e simplesmente uma das figuras do moderno:

Isso posto, não está anulada a impressão de dualidade e contradição que o país não cessa de renovar. $O$ antigo e o novo continuam em presença um do outro - é o que parece mostrar a experiência social de todos os dias, sobretudo quando filtrada pela forma estética - muda apenas o plano de sua relação. Somos de fato produto do movimento internacional do capital, mas embora este se desenrole em escala mundial, vai compondo elementos que são diferentes e assimétricos; distinguimo-nos assim do padrão geral na medida em que a primitiva exploração colonial está na base da articulação entra sociedades dependentes e dominantes. Mas a que se resume a singularidade do país senão a essa coexistência, sistemática, descompartimentada, de herança colonial e presente capitalista? Acrescida do fato de que a referida herança também era um legado de formas pretéritas da expansão capitalista. (ARANTES, 1992, p. 38)

Ainda seguindo a nossa hipótese inicial, essa contradição cotidiana expressaria a nossa formação social e caracterizaria os vetores básicos 
da experiência histórica brasileira, estando também presente na subjetividade social, que viria desaguar em processos presentes até hoje. Seria o testemunho de que a formação - a integração social e cultural modelada à forma europeia, mas com lógica e dinamismo próprios -, tal qual idealizada pelos ciclos de modernização, ruiu e ao mesmo tempo elabora o que se poderia chamar de uma formação trágica, que se serve das ruínas daquela primeira. Porém, como verdadeiros irmãos inimigos, a coincidência de propósitos é também uma luta de morte. A criação de uma visão da sociedade brasileira que incorpora precariedade, exclusão e violência é testemunho da total falência daquela outra formação, que ela mimetiza tragicamente - formação da promessa de integração social, da universalização dos direitos, da igualdade perante a lei, da democratização da cultura, do país como paraíso do futuro:

Noutras palavras, a falência do desenvolvimentismo, o qual havia revolvido a sociedade de alto a baixo, abre um período específico, essencialmente moderno, cuja dinâmica é a desagregação. Se for assim, o que está na ordem do dia não é o abandono das ilusões nacionais, mas sim a sua crítica especificada, o acompanhamento de sua desintegração, a qual é um dos conteúdos reais e momentosos de nosso tempo. (SCHWARZ, 1999, p. 160, grifos do autor)

Em vez do indivíduo tradicional, estaríamos, em Grande sertão Grajaú, diante de personagens que reproduzem uma espécie de modelo de personalidade agônica, em vias de aniquilamento - neste sentido, muito próximos do sujeito-consumidor de hoje, habitado, em dissolução contínua, pelas vozes furiosas da mercadoria.

\section{Referências bibliográficas}

II TRUPE DE CHOQUE. Grande sertão Grajaú: veredas e ruínas [manuscrito]. São Paulo, 2016.

ARANTES, P. E. Sentimento da dialética. São Paulo: Paz e Terra, 1992.

BOLLE, W. grandesertão.br: o romance de formação do Brasil. São Paulo: Editora 34, 2004.

CANDIDO, Antonio. Formação da literatura brasileira. Belo Horizonte: Itatiaia; São Paulo: Edusp, 1975. 
FAORO, R. Os donos do poder: formação do patronato político brasileiro. São Paulo: Globo, 2008.

FOUCAULT, M. Do governo dos vivos: curso no Collège de France (1979-1980). São Paulo: WMF Martins Fontes, 2014.

FREYRE, G. Casa-grande \& senzala. São Paulo: Global, 2004.

FURTADO, C. Formação econômica do Brasil. São Paulo: Companhia das Letras, 2011.

HOLANDA, S. B. Raízes do Brasil. São Paulo: Companhia das Letras, 2005.

KANT, I. O que é esclarecimento?. Rio de Janeiro: Via Verita, 2016.

LACAN, J. Subversão do sujeito e dialética do desejo no inconsciente freudiano. In: . Escritos. Rio de Janeiro: Zahar, 1999.

MARTINS PENA, L.C. Comédias de Martins Pena. Rio de Janeiro: Ediouro, 1990.

OLIVEIRA, F. Crítica à razão dualista: o Ornitorrinco. São Paulo: Boitempo, 2003.

PASTA JR., José Antonio. "O romance de Rosa". Novos Estudos CEBRAP, n. 55, p. 61-70, nov. 1999.

PRADO Jr., C. Formação do Brasil contemporâneo. São Paulo: Brasiliense/ Publifolha, 2000.

ROSA, J. G. Grande sertão: veredas. Rio de Janeiro: Nova Fronteira, 2001.

SCHWARZ, R. Sequências brasileiras. São Paulo: Companhia das Letras, 1999.

SZONDI, P. Ensaio sobre o trágico. São Paulo: Zahar, 2004

VIANNA FILHO, O. Os Azeredo mais os Benevides. Rio de Janeiro: MEC/SNT, 1968.

ZIZEK, S. Viver no fim dos tempos. Lisboa: Relógio d'água, 2011.

Órganos sin cuerpo. Valencia: Pre-textos, 2006.

Recebido em 05/09/2016

Aprovado em 03/05/2018

Publicado em 29/06/2018 